To cite: Guarino M, Gambuti E, Alfano $\mathrm{F}$, et al. Life-threatening onset of coeliac disease: a case report and literature review. BMJ Open Gastro 2020;0:e000406. doi:10.1136/ bmjgast-2020-000406

Received 19 March 2020

Revised 7 April 2020

Accepted 8 April 2020

\section{Check for updates}

(c) Author(s) (or their employer(s)) 2020. Re-use permitted under CC BY-NC. No commercial re-use. See rights and permissions. Published by BMJ.

${ }^{1}$ Department of Morphology, Surgery and Experimental Medicine, University of Ferrara, Ferrara, Italy

${ }^{2}$ Department of Emergency Medicine, St. Anna University Hospital, Ferrara, Italy ${ }^{3}$ Department of Medicine, A.O.U.I. Policlinico G.B. Rossi and University of Verona, Verona, Italy

${ }^{4}$ Department of Medical and Surgical Sciences, University of Bologna, Bologna, italy

${ }^{5}$ Celiac Center and Mucosal Immunology and Biology Reaserch Center, Massachusetts General Hospital - Harvard Medical School, Boston, MA, United States

Correspondence to Dr Giacomo Caio; caigmp@unife.it

\title{
Life-threatening onset of coeliac disease: a case report and literature review
}

\author{
Matteo Guarino, ${ }^{1}$ Edoardo Gambuti, ${ }^{1}$ Franco Alfano, ${ }^{1}$ Andrea Strada, ${ }^{2}$ \\ Rachele Ciccocioppo (1) , ${ }^{3}$ Lisa Lungaro, ${ }^{1}$ Giorgio Zoli, ${ }^{1}$ Umberto Volta, ${ }^{4}$ \\ Roberto De Giorgio, ${ }^{1}$ Giacomo Caio (D) ${ }^{1,5}$
}

\section{ABSTRACT}

Background Coeliac disease (CD) results from an immune-mediated reaction to gluten in genetically predisposed individuals. In rare cases CD may occur with acute features deferring the diagnosis and exposing these patients to possible life-threatening complications. Herein we present the case of a young woman with a coeliac crisis, that is, a sudden clinical onset characterised by severe electrolyte imbalance due to an unknown (previously unrecognised) CD.

Methods This is a case report and literature review revealing that coeliac crisis is under-reported, with a total of 48 adult cases so far published. The diagnosis in our case was established by histopathological analysis of multiple duodenal biopsies. The patient's serum was tested by enzyme-linked immunoassay to detect antitransglutaminase IgA antibodies.

Results In contrast to cases reported in the literature, with male gender predominance and a mean age of $50 \pm 17$ years, our patient was a young female case of coeliac crisis. However, like in our patient, a higher incidence of coeliac crisis was associated with the human leucocyte antigen (HLA)-DQ2 haplotype, versus HLA-DQ8, and a severe (Marsh-Oberhüber $3 \mathrm{c}$ ) duodenal mucosa atrophy. Notably, there is no clear correlation between the antitissue transglutaminase $2 \lg A$ antibody titre and coeliac crisis onset/severity, as confirmed by our case report.

Conclusions The present case highlights that CD may manifest quite abruptly with a severe malabsorption syndrome, that is, electrolyte abnormalities and hypoproteinaemia. Our case should alert physicians, in particular those in the emergency setting, that even a typically chronic disorder, such as CD, may show lifethreatening complications requiring urgent management.

\section{INTRODUCTION}

Coeliac disease (CD) is a multisystemic, immune-mediated illness evoked by gluten ingestion in genetically susceptible individuals. ${ }^{1}$ The main target organ of the autoimmune reaction against the enzyme tissue transglutaminase (TG2) is the small bowel, where the gluten-related inflammatory cascade causes a progressive mucosal damage leading to severe villous atrophy. ${ }^{1}{ }^{2}$ From a clinical standpoint, CD is a multifaceted chronic condition displaying a broad spectrum of intestinal (ranging from mild irritable bowel syndrome-like to severe malabsorption symptoms) and extraintestinal manifestations targeting several tissues and organs (eg, skin, endocrine/exocrine glands, nervous system, joint/muscles). As a result, CD remains a challenging condition to be diagnosed, thus causing a significant delay in establishing the appropriate therapy and increasing related morbidity. ${ }^{3-5}$

A potentially life-threatening neglected clinical manifestation of $\mathrm{CD}$ is the so-called 'coeliac crisis', characterised by acute, massive watery diarrhoea, severe dehydration and metabolic disturbances, leading to neuromuscular weakness, tetanic seizures, cardiac arrhythmias and even sudden death in extreme cases. ${ }^{6-8}$ This condition is largely under-reported and under-recognised both in children and adults, with a total of 48 adult cases published so far. ${ }^{6-46}$ In most cases, coeliac crisis develops due to voluntary or inadvertent gluten ingestion in patients with or without an established diagnosis of CD. Only rarely a coeliac crisis heralds the clinical onset of $\mathrm{CD}$, requiring hospitalisation and rapid therapeutic management due to possible occurrence of severe complications with high morbidity and mortality. ${ }^{9-13}$

Herein we describe the case of a patient admitted to our emergency department for a severe life-threatening coeliac crisis as the first manifestation of a previously unknown CD.

\section{CASE REPORT}

A 34-year-old woman was admitted to the emergency unit complaining of limb 


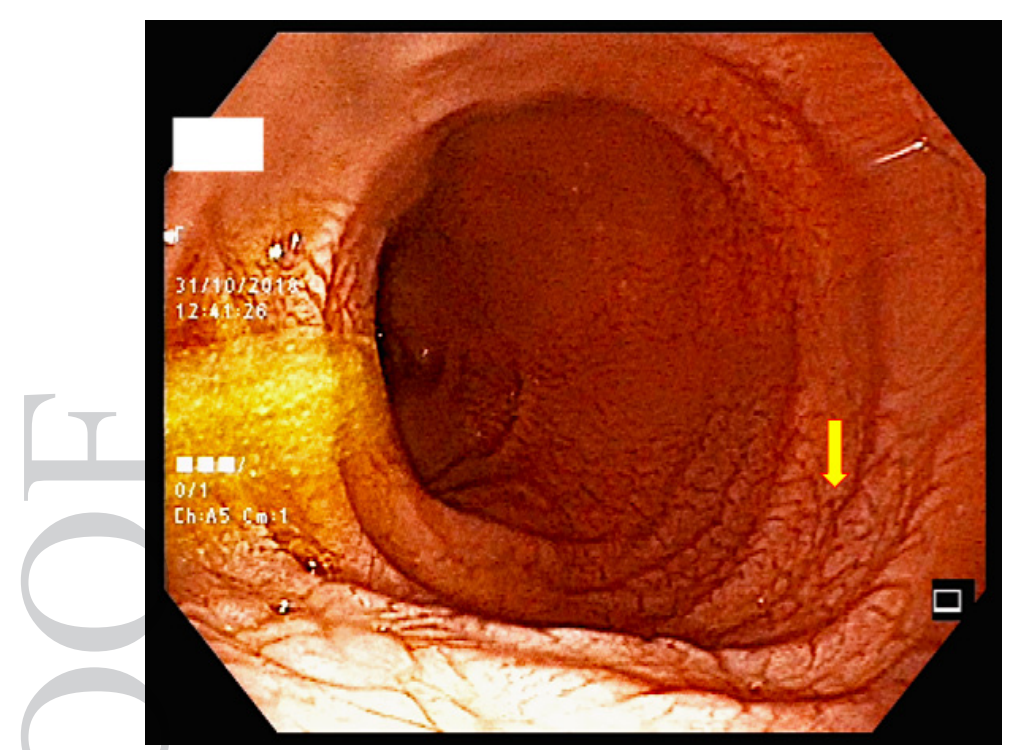

Figure 1 Representative duodenal endoscopic picture showing decreased mucosal folds carrying a scalloping profile, together with a mosaic pattern and an increased vascular network (arrow), all suggestive of villous atrophy.

numbness and watery diarrhoea (8-10 bowel movements/day) which started 2 weeks earlier. The patient reported a weight loss of about $10 \mathrm{~kg}$ in the last 2 months in the absence of hyporexia. Her clinical history unravelled microcytic anaemia treated with oral iron replacement. Physical examination showed severe weakness of the limbs with a bilaterally positive Trousseau's sign without cardiorespiratory abnormalities. Vital parameters were within the normal range. The abdomen was flat, without tenderness, while auscultation disclosed increased intestinal sounds. Her ECG showed a sinus rhythm with type 1 atrioventricular block, flat $\mathrm{T}$ waves associated with $\mathrm{U}$ waves and an elongated QTc interval

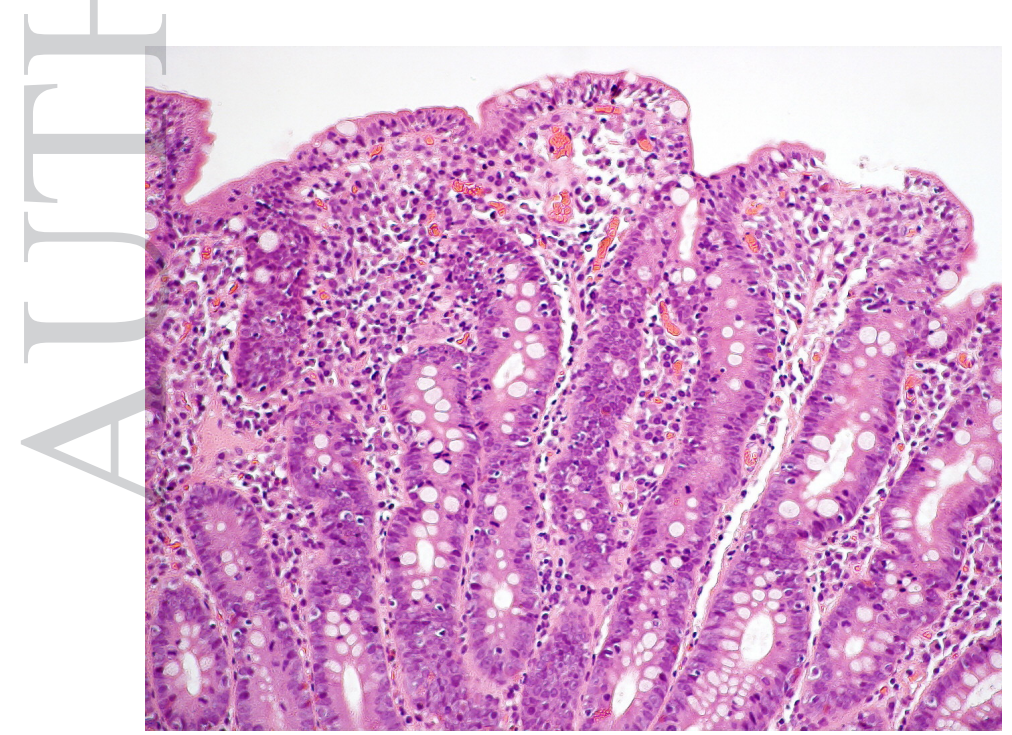

Figure 2 Representative microphotograph of the duodenal mucosa showing villous atrophy and crypt hyperplasia with dense inflammatory infiltrate of the lamina propria (Marsh-Oberhüber lesion grade 3c). H\&E staining, original magnification $200 \times$.
(570 ms). Laboratory tests revealed severe electrolyte imbalance, with hyponatraemia $(133 \mathrm{mmol} / \mathrm{L})$, hypokalaemia $(1.6 \mathrm{mmol} / \mathrm{L})$, hypocalcaemia (ionised calcium of $0.9 \mathrm{mmol} / \mathrm{L})$, hypophosphataemia (1.6 mg/ $\mathrm{dL})$ and hypomagnesaemia $(1.4 \mathrm{mmol} / \mathrm{L})$. Furthermore, the patient had hypochromic microcytic anaemia (haemoglobin of $85 \mathrm{~g} / \mathrm{L}$, with a mean cell volume of $68 \mathrm{fL}$ and a mean cell haemoglobin of $20.6 \mathrm{pg}$ ), normal platelet count $\left(297 \times 10^{\wedge} 9 / \mathrm{L}\right)$, iron (serum iron $18 \mu \mathrm{g}$ / $\mathrm{dL}$; ferritin $2 \mathrm{ng} / \mathrm{mL})$ and folate deficiency $(2 \mathrm{ng} / \mathrm{mL})$, as well as hypoproteinaemia and hypoalbuminaemia (total serum protein $4.4 \mathrm{~g} / \mathrm{dL}$; albumin $2.6 \mathrm{~g} / \mathrm{dL}$ ). Due to severe electrolyte imbalance, a conspicuous electrolyte replacement was rapidly administered, leading to a slight improvement in electrocardiographic abnormalities. The patient was then admitted to the internal medicine ward for adequate investigation and treatment. During the hospitalisation, the common causes of infectious diarrhoea were excluded by stool cultures, and the faecal occult blood test resulted negative. Both ultrasound and abdominal X-ray examinations were unremarkable. Liver function tests revealed a slight increase of transaminases, with alanine transaminase and aspartate transaminase values of $47 \mathrm{U} / \mathrm{L}$ and $60 \mathrm{U} / \mathrm{L}$ (n.v. 5-35 for both parameters), respectively. Based on the lack of fever, normal $\mathrm{C}$ reactive protein and the presence of non-bloody, watery diarrhoea, the patient was further evaluated with an upper endoscopy. The examination revealed stigmata of villous atrophy at the duodenal level (figure 1), where biopsies were taken from the bulb and the second portion. Histopathological analysis showed the presence of a severe villous atrophy (Marsh-Oberhüber grade 3c) (figure 2) without any evidence of aberrant intraepithelial lymphocytes. ${ }^{14}$ Based on the histopathological result, we used enzyme-linked immunoassay to test IgA antiTG2, which turned to be positive at low titre $(23 \mathrm{U} / \mathrm{mL}$, n.v. $<10 \mathrm{U} / \mathrm{mL})$. This result was associated with the positivity of IgA antiendomysial antibodies (1:80) revealed by indirect immunofluorescence. ${ }^{47} 48$ The genetic test showed human leucocyte antigen (HLA)-DQ2 positivity. Therefore, a firm diagnosis of CD was established and the patient started a gluten-free diet (GFD). Due to rapid improvement after gluten withdrawal, a course with steroid treatment was deemed not necessary. Since diarrhoea and paraesthesia showed significant improvement with complete regression in about a week, the patient was discharged in good health.

\section{DISCUSSION AND REVIEW OF THE LITERATURE}

In the vast majority of cases, the natural history of CD is characterised by chronic evolution without acute exacerbations. Conversely, coeliac crisis is burdened by severe acute symptoms such as abdominal pain and distension, massive diarrhoea and weight loss, causing a life-threatening malabsorption syndrome. In most cases, gluten is introduced inadvertently, whereas in some patients with poor compliance to GFD a voluntary 


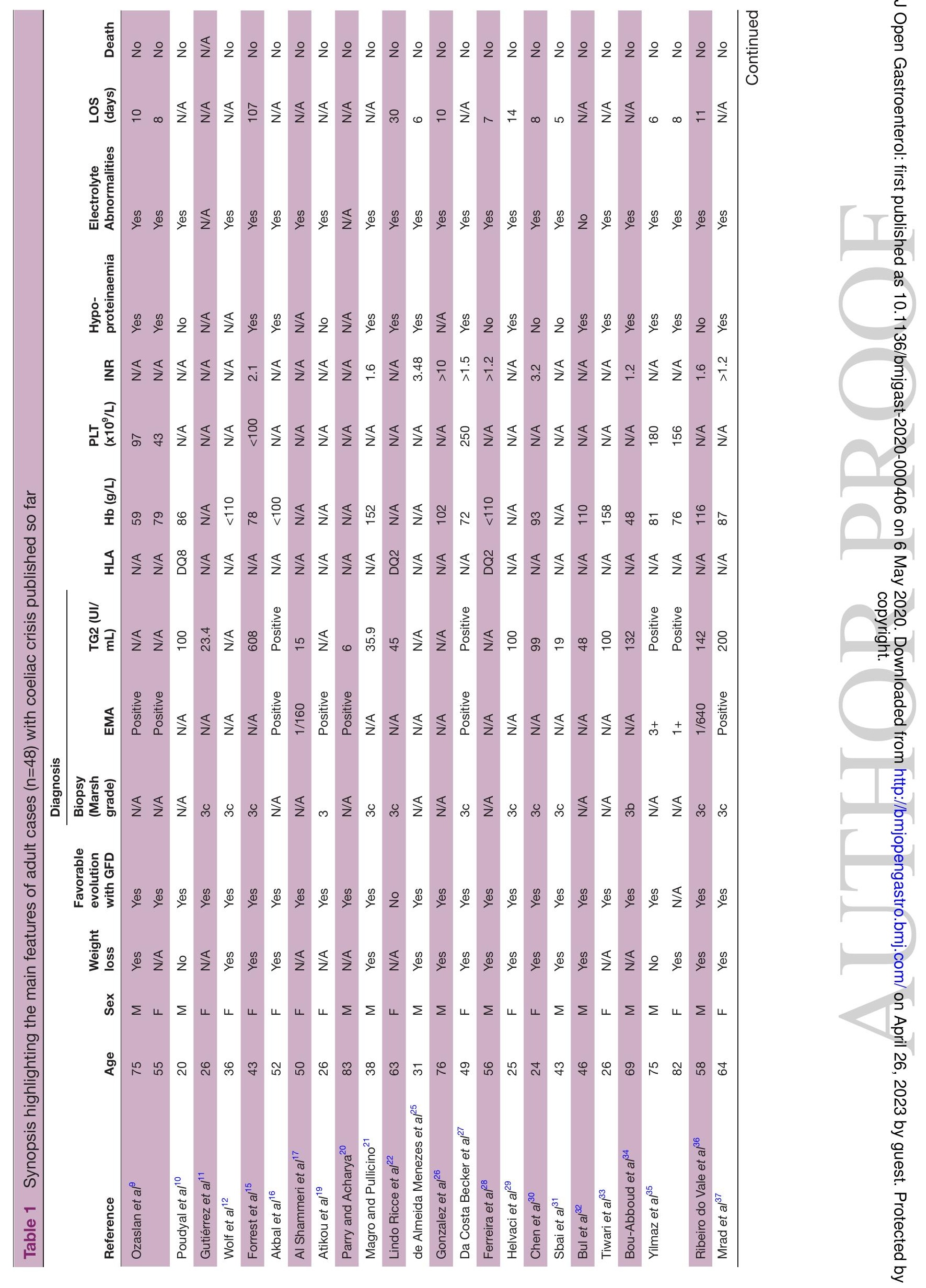




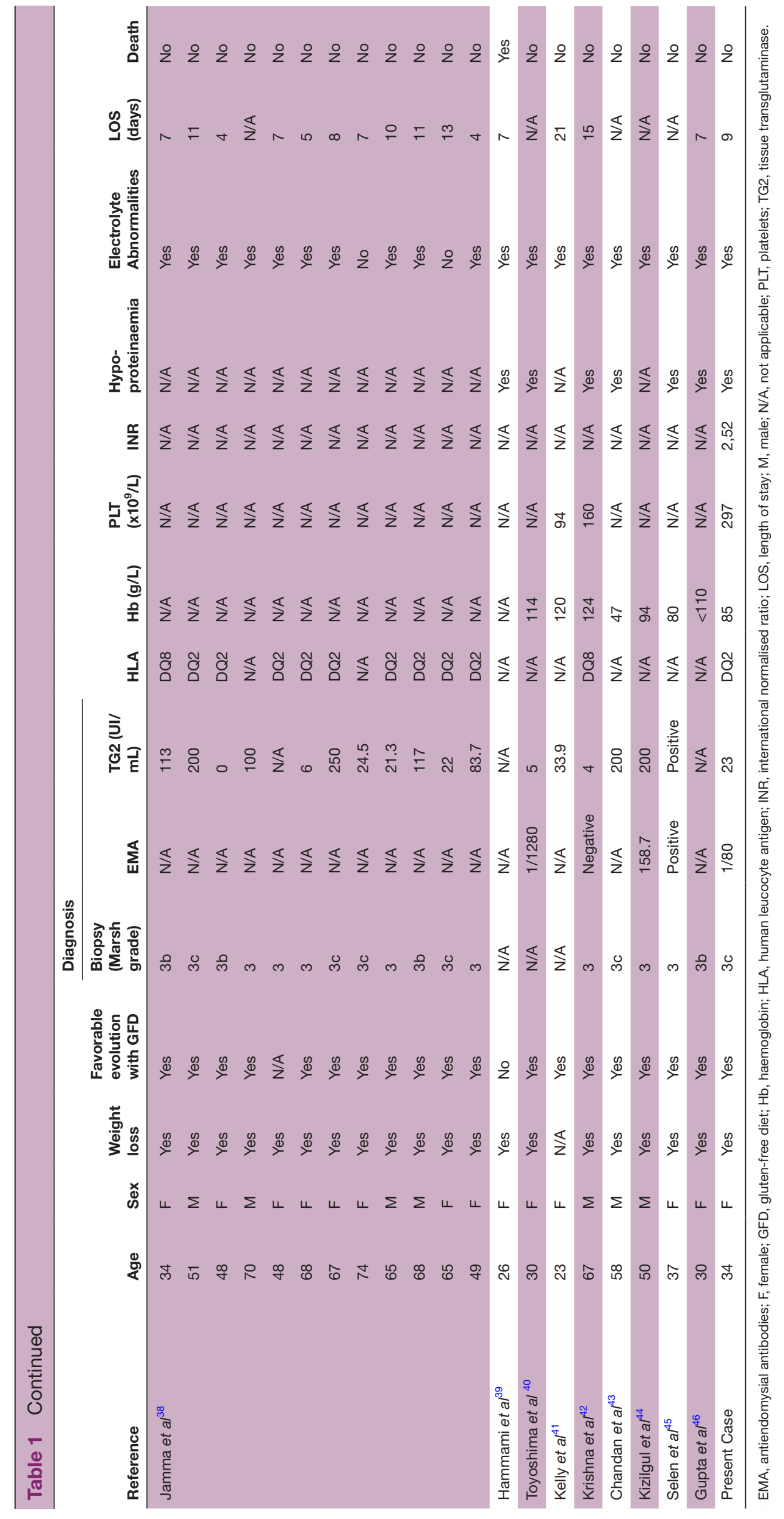


ingestion may occur. ${ }^{367}$ Only seldom a coeliac crisis can herald the onset of $\mathrm{CD},{ }^{10}$ as it was in the herein reported case. Among the reported cases described in table 1, there was a greater prevalence of female than male gender (28 vs 20 ), with a mean age of $50 \pm 17$ years, which is higher than the age of the present case. ${ }^{9-46}$ Like in the present case, a higher incidence of coeliac crisis has been reported in patients carrying the HLA-DQ2 haplotype of genetic susceptibility to the disease as compared with those with HLA-DQ8, whereas the biopsy specimens showed signs characteristic of Marsh-Oberhüber 3 (from 'a' to 'c') mucosal lesions. ${ }^{1}$ Other common clinical features included weight loss, hypoproteinaemia and electrolyte abnormalities, whereas coagulation abnormalities (ie, prothrombin time elongation) along with markedly reduced platelet count were uncommon. No clear correlation was found between the anti-TG2 IgA antibody titre and coeliac crisis onset/severity, as also supported by our case showing only a twofold increase above the upper normal limit.

Among the major features of this case were the abrupt onset of symptoms, in particular of those related to electrolyte imbalance, and the severity of the clinical picture prompting admission to the emergency department. Further to severe dehydration, the patient presented with neuromuscular weakness, a finding detected in other reports, ${ }^{7} 9$ 13-21 and electrocardiographic abnormalities due to the key role exerted by potassium in regulating cell excitability. Likely, hypocalcaemia and hypomagnesaemia also contributed to worsening cellular excitability. According to previous evidence, ${ }^{6-13}$ hypoproteinaemia with hypalbuminaemia and metabolic acidosis were found in our patient as hallmarks of malabsorption, whereas paraesthesia was likely related to electrolyte imbalance. However, the variety of possible clinical pictures in coeliac crisis should be underlined, ranging from central nervous system involvement with tetraplegia/paraplegia and ataxia, ${ }^{17-19}$ psychosis ${ }^{22}$ as well as seizures, ${ }^{23} 24$ to coagulopathy $^{11}{ }^{25-27}$ and acute kidney injury. ${ }^{28} 29$ In all cases described so far, coeliac crisis required urgent hospitalisation. The milestone treatment is fluid resuscitation with correction of the electrolyte imbalance, which can lead to life-threatening cardiac arrhythmias. Nutritional support is also of paramount importance, and clinicians should take coeliac crisis in mind during differential diagnosis of severe acute diarrhoea with weight loss, as patients' prognosis can dramatically improve with a simple dietary intervention.

In our case, like in almost all cases described, GFD led to a dramatic improvement in clinical picture. Nutritional management should take into consideration the possible occurrence of a refeeding syndrome, which can be fatal if not recognised and treated properly, as described in one patient with coeliac crisis. ${ }^{39}$ In less than $20 \%$ of cases ( 8 of 48 cases, $16 \%$ ), corticosteroids were administered during management. ${ }^{49}$ However, we decided not to use steroids since their usefulness was recently questioned. ${ }^{38} 50$ It was reported previously that immunosuppression with corticosteroids and azathioprine for autoimmune hepatitis or prednisone for Bell's palsy did not prevent the occurrence of coeliac crisis in patients. ${ }^{17} 51$ Moreover, steroid therapy may increase electrolyte depletion, facilitating the occurrence of refeeding syndrome. ${ }^{22}$ Finally, despite the acute onset of malabsorption syndrome in adulthood, our case did not show features of complicated $\mathrm{CD}^{52} 53$ (ie, refractory $\mathrm{CD}$ ), and the clinical picture dramatically improved in a few days with GFD, still the only effective treatment available. ${ }^{54}$

\section{CONCLUSION}

The present case highlights the possibility that CD may manifest quite abruptly with a severe malabsorption syndrome and related electrolyte abnormalities and hypoproteinaemia. This would imply that even a typically chronic disorder, such as CD, may have an acute onset in a small proportion of patients, which emergency physicians should be aware of. Although rarely encountered in clinical practice, this acute onset of $\mathrm{CD}$ requires hospitalisation and immediate treatment (ie, electrolyte replacement and protein correction) in order to avoid life-threatening complications.

Contributors MG, RDG and GC: design and conceptualisation. MG, EG and FA reviewed the literature and wrote the first draft of the manuscript. AS, RC, LL, GZ, UV, RDG and GC participated in the clinical assessment of the patient and critically reviewed the paper.

Funding The authors have not declared a specific grant for this research from any funding agency in the public, commercial or not-for-profit sectors.

Competing interests None declared.

Patient consent for publication Obtained.

Provenance and peer review Not commissioned; externally peer reviewed.

Data availability statement Data sharing not applicable as no data sets generated and/or analysed for this study.

Open access This is an open access article distributed in accordance with the Creative Commons Attribution Non Commercial (CC BY-NC 4.0) license, which permits others to distribute, remix, adapt, build upon this work non-commercially, and license their derivative works on different terms, provided the original work is properly cited, appropriate credit is given, any changes made indicated, and the use is non-commercial. See: http://creativecommons.org/licenses/by-nc/4.0/.

ORCID iDs

Rachele Ciccocioppo http://orcid.org/0000-0002-6297-7576

Giacomo Caio http://orcid.org/0000-0002-4244-4529

\section{REFERENCES}

1 Caio G, Volta U, Sapone A, et al. Celiac disease: a comprehensive current review. BMC Med 2019;17:142.

2 Valitutti F, Fasano A. Breaking down barriers: how understanding celiac disease pathogenesis informed the development of novel treatments. Dig Dis Sci 2019;64:1748-58.

3 Trovato CM, Raucci U, Valitutti F, et al. Neuropsychiatric manifestations in celiac disease. Epilepsy Behav 2019;99:106393.

4 Volta U, Caio G, Stanghellini V, et al. The changing clinical profile of celiac disease: a 15-year experience (1998-2012) in an Italian referral center. BMC Gastroenterol 2014;14:194.

5 Caio G, Volta U. Coeliac disease: changing diagnostic criteria? Gastroenterol Hepatol Bed Bench 2012;5:119-22.

6 Waheed N, Cheema HA, Suleman H, et al. Celiac crisis: a rare or rarely recognized disease. J Ayub Med Coll Abbottabad 2016;28:672-5. 
7 Mones RL, Atienza KV, Youssef NN, et al. Celiac crisis in the modern era. J Pediatr Gastroenterol Nutr 2007;45:480-3.

8 Rostami-Nejad M, Villanacci V, Hogg-Kollars S, et al. Endoscopic and histological pitfalls in the diagnosis of celiac disease: a multicentre study assessing the current practice. Rev Esp Enferm Dig 2013;105:326-33.

9 Ozaslan E, Köseoğlu T, Kayhan B. Coeliac crisis in adults: report of two cases. Eur J Emerg Med 2004;11:363-5.

10 Poudyal R, Lohani S, Kimmel WB. A case of celiac disease presenting with celiac crisis: rare and life threatening presentation. $J$ Community Hosp Intern Med Perspect 2019;9:22-4.

11 Gutiérrez S, Toro M, Cassar A, et al. [Celiac crisis: presentation as bleeding diathesis]. Acta Gastroenterol Latinoam 2009;39:53-4.

12 Wolf I, Mouallem M, Farfel Z. Adult celiac disease presented with celiac crisis: severe diarrhea, hypokalemia, and acidosis. J Clin Gastroenterol 2000;30:324-6.

13 Altamimi E. Celiac crisis with severe hypokalemia and paraplegia as a first presentation of celiac disease in a child. Jordan Med $J$ 2012;46:61-3.

14 Oberhuber G, Granditsch G, Vogelsang H. The histopathology of coeliac disease: time for a standardized report scheme for pathologists. Eur J Gastroenterol Hepatol 1999;11:1185.

15 Forrest EA, Wong M, Nama S, et al. Celiac crisis, a rare and profound presentation of celiac disease: a case report. BMC Gastroenterol 2018;18:59.

16 Akbal E, Erbağ G, Binnetoğlu E, et al. An unusual gastric ulcer cause: celiac crisis. Wien Klin Wochenschr 2014;126:661-2.

17 Al Shammeri O, Duerksen DR. Celiac crisis in an adult on immunosuppressive therapy. Can J Gastroenterol 2008;22:574-6.

18 Oba J, Escobar AM, Schvartsman BGS, et al. Celiac crisis with ataxia in a child. Clinics 2011;66:173-5.

19 Atikou A, Rabhi M, Hidani $\mathrm{H}$, et al. [Celiac crisis with quadriplegia due to potassium depletion as presenting feature of celiac disease]. Rev Med Interne 2009;30:516-8.

20 Parry J, Acharya C. Celiac crisis in an older man. celiac crisis in an older man. Am Geriatr Soc 2010;58:1818-9.

21 Magro R, Pullicino E. Coeliac crisis with severe hypokalaemia in an adult. Malta Medical Journal 2012;24:36-9.

22 Lindo Ricce M, Rodriguez-Batllori Arán B, Jiménez Gómez M, et al. Enfermedad celíaca no respondedora: crisis celíaca vs. enfermedad celíaca refractaria Con respuesta a corticoides. Gastroenterología y Hepatología 2017;40:529-30.

23 Hijaz NM, Bracken JM, Chandratre SR. Celiac crisis presenting with status epilepticus and encephalopathy. Eur J Pediatr 2014;173:1561-4.

24 Caio G, De Giorgio R, Venturi A, et al. Clinical and immunological relevance of anti-neuronal antibodies in celiac disease with neurological manifestations. Gastroenterol Hepatol Bed Bench 2015;8:146-52.

25 de Almeida Menezes M, Cabral V, Silva Lorena SL. Celiac crisis in adults: a case report and review of the literature focusing in the prevention of refeeding syndrome. Rev Esp Enferm Dig 2017;109:67-8.

26 Gonzalez JJ, Elgamal M, Mishra S, et al. Severe coagulopathy as a rare feature of celiac crisis in a patient previously diagnosed with celiac disease. Am J Case Rep 2019:20:290-3.

27 Da Costa Becker SM, Appel-da-Silva MC, D'Incao RB, et al. Celiac crisis and hemorrhagic diathesis in an adult. Scientia Medica 2014;24:284-7.

28 Ferreira R, Pina R, Cunha N, et al. A celiac crisis in an adult: raising awareness of a life-threatening condition. Eur J Case Rep Intern Med 2016;3:000384.

29 Helvacı Özant, Yıldız S, Korucu B, et al. Coeliac crisis mimicking nephrotic syndrome in a post-partum patient. Scott Med J 2019;64:116-8.

30 Chen A, Linz CM, Tsay JL, et al. Celiac crisis associated with herpes simplex virus esophagitis. ACG Case Rep J 2016;3:e159.

31 Sbai W, Bourgain G, Luciano L, et al. Celiac crisis in a multi-trauma adult patient. Clin Res Hepatol Gastroenterol 2016;40:e31-2.
32 Bul V, Sleesman B, Boulay B. Celiac Disease Presenting as Profound Diarrhea and Weight Loss - A Celiac Crisis. Am J Case Rep 2016;17:559-61.

33 Tiwari A, Qamar K, Sharma H, et al. Urinary tract infection associated with a celiac crisis: a preceding or precipitating event? Case Rep Gastroenterol 2017;11:364-8.

34 Bou-Abboud C, Katz J, Liu W. Firing of an implantable cardiac defibrillator: an unusual presentation of celiac crisis. ACG Case Rep J 2016;3:e137.

35 Yilmaz B, Aksoy EK, Kahraman R, et al. Atypical presentation of celiac disease in an elderly adult: celiac crisis. J Am Geriatr Soc 2015;63:1712-4.

36 Ribeiro do Vale R, da Silva Conci N, Santana AP, et al. Ls Laborda and Felipe dA Silva as. celiac crisis: an unusual presentation of gluten-sensitive enteropathy. Autopsy Case Rep 2018;8:e2018027.

37 Mrad RA, Ghaddara HA, Green PH, et al. Celiac crisis in a 64-yearold woman: an unusual cause of severe diarrhea, acidosis, and malabsorption. ACG Case Reports Journal 2015;2:95-7.

38 Jamma S, Rubio-Tapia A, Kelly CP, et al. Celiac crisis is a rare but serious complication of celiac disease in adults. Clin Gastroenterol Hepatol 2010;8:587-90.

39 Hammami S, Aref HL, Khalfa M, et al. Refeeding syndrome in adults with celiac crisis: a case report. J Med Case Rep 2018;12:22.

40 Toyoshima MTK, Queiroz MS, Silva MER, et al. Celiac crisis in an adult type 1 diabetes mellitus patient: a rare manifestation of celiac disease. Arq Bras Endocrinol Metab 2013;57:650-2.

41 Kelly E, Cullen G, Aftab AR, et al. Coeliac crisis presenting with cytomegalovirus hepatitis. Eur J Gastroenterol Hepatol 2006;18:793-5.

42 Krishna K, Krishna SG, Coviello-malle JM, et al. Celiac crisis in a patient with chronic lymphocytic leukemia and hypogammaglobulinemia. Clin Res Hepatol Gastroenterol 2011;35:70-3.

43 Chandan S, Ahmad D, Hewlett A. Celiac crisis: a rare presentation of celiac disease in adults. 2016.. ACG 2016 conference paper.

44 Kizilgul M, Kan S, Celik S, et al. Celiac crisis in an adult type 1 diabetes mellitus patient presented with diarrhea, weight loss and hypoglycemic attacks. Int J Diabetes Dev Ctries 2017;37:85-7.

45 Selen T, Ince M, Çelik S, et al. Gluten sensitive enteropathy presenting with celiac crisis as the initial presentation: case report. Turkiye Klinikleri Journal of Gastroenterohepatology 2014;21:60-2.

46 Gupta T, Mandot A, Desai D, et al. Celiac crisis with hypokalemic paralysis in a young lady. Indian J Gastroenterol 2006;25:259-60.

47 Volta U, Fabbri A, Parisi C, et al. Old and new serological tests for celiac disease screening. Expert Rev Gastroenterol Hepatol 2010:4:31-5

48 Amarri S, Alvisi P, De Giorgio R, et al. Antibodies to deamidated gliadin peptides: an accurate predictor of coeliac disease in infancy. J Clin Immunol 2013:33:1027-30.

49 Balaban DV, Dima A, Jurcut C, et al. Celiac crisis, a rare occurrence in adult celiac disease: a systematic review. WJCC 2019;7:311-9.

50 Gupta S, Kapoor K. Steroids in celiac crisis: doubtful role! Indian Pediatr 2014;51:756-7

51 Volta U, Caio G, Tovoli F, et al. Gut-liver axis: an immune link between celiac disease and primary biliary cirrhosis. Expert Rev Gastroenterol Hepatol 2013;7:253-61.

52 Caio G, Volta U, Ursini F, et al. Small bowel adenocarcinoma as a complication of celiac disease: clinical and diagnostic features. BMC Gastroenterol 2019;19:45.

53 Vanoli A, Di Sabatino A, Furlan D, et al. Small Bowel Carcinomas in Coeliac or Crohn's Disease: Clinico-pathological, Molecular, and Prognostic Features. A Study From the Small Bowel Cancer Italian Consortium. J Crohns Colitis 2017;11:942-53.

54 Caio G, Ciccocioppo R, Zoli G, et al. Therapeutic options for coeliac disease: what else beyond gluten-free diet? Digestive and Liver Disease 2020;52:130-7. 